\title{
PENGARUH EFIKASI DIRI TERHADAP COMMUNICATION APPREHENSION PADA MAHASISWA BARU TAHUN PERTAMA UNIVERSITAS MUHAMMADIYAH RIAU
}

\section{The Effect of Self-Efficacy on Communication Apprehension on Riau Muhammadiyah University's First Year Students}

\author{
Nur Fitriyana ${ }^{1} \&$ Puti Febrina Niko ${ }^{2}$ \\ ${ }^{12}$ Program Studi Psikologi Islam, Universitas Muhammadiyah Riau
}

Diterima 30 September 2020 / Disetujui 30 Oktober 2020

\begin{abstract}
The ability to communicate well is an important asset in the process of disseminating information, knowledge and supporting the learning process on campus, especially in expressing ideas to others. Different activities when sitting in school, in higher education a student is required to be more active in the teaching and learning process and to be more independent in finding lecture information. Therefore, students who are just entering the world of campus must be able to adapt to the existing patterns on campus. The purpose of this study was to see the effect of self-efficacy on communication worries in freshmen first year. This study used a survey study with a research scale. The study population was university students. The sampling technique used in this study was quota random sampling. The data collection technique uses simple linear regression analysis techniques. The variables in this study consisted of the dependent variable (communication anxiety) and the independent variable (self-efficacy). The results of this study found that self-efficacy had an influence on communication concerns among new first year students of Riau Muhammadiyah University. Table 1 shows that $r$ is 0.503 with a significance of 0.000. This shows that there is an effect of self-efficacy on communication concerns among new first year students of Riau Muhammadiyah University. From the results of the simple regression test that the selfefficacy variable has an effect on understanding communication by $17.3 \%$, while the remaining $82.7 \%$ is by other factors that do not apply in this study. The coefficient score of the effect of self-efficacy which has a percentage shows a score that is negative towards communication concerns. This may imply that the higher the self-efficacy, the lower the communication worries and vice versa

Keywords: college students, communication apprehension, self-efficacy
\end{abstract}

\begin{abstract}
ABSTRAK
Kemampuan berkomunikasi yang baik merupakan merupakan modal yang penting dalam proses penyebaran informasi, ilmu pengetahuan dan menunjang proses pembelajaran di kampus khususnya dalam mengekspresikan gagasan kepada orang lain. Beda halnya pada waktu duduk dibangku sekolah, di Perguruan tinggi seorang mahasiswa dituntut agar bisa lebih berperan aktif dalam proses belajar mengajar serta lebih mandiri dalam mencari informasi-informasi perkuliahan. Oleh karena itu, mahasiswa yang baru memasuki dunia kampus harus mampu beradaptasi dengan pola yang ada di kampus. Tujuan dari penelitian ini adalah untuk melihat pengaruh efikasi diri terhadap communication apprehension pada mahasiswa baru tahun pertama. Penelitian ini menggunakan kajian survey dengan skala penelitian. Populasi penelitian merupakan mahasiswa tahun. Teknik pengambilan sampel digunakan dalam penelitian ini yaitu quota random sampling. Teknik pengelohan data menggunakan teknik analisis regresi linier sederhana. Variabel dalam penelitian ini terdiri dari variabel tergantung (communication apprehension) dan variabel bebas (efikasi diri). Adapun hasil dari penelitian ini didapatkan bahwa efikasi diri memiliki pengaruh terhadap communication apprehension pada mahasiswa baru tahun pertama Universitas Muhammadiyah Riau. Pada tabel 1 menunjukan $r$ yaitu 0,503 dengan signifikansi 0,000. Hal ini menunjukan bahwa ada pengaruh efikasi diri terhadap communication apprehension pada mahasiswa baru tahun pertama Universitas Muhammadiyah Riau. Dari hasil uji regresi sederhana bahwa variable efikasi diri berpengaruh terhadap communication apprehension sebesar $17,3 \%$ sedangkan sisanya $82,7 \%$ dipengaruhi oleh faktor lain yang tidak dijelaskan dalam penelitian ini. Skor koefisien pengaruh efikasi
\end{abstract}


diri memiliki persentasi menunjukan skor yang berarah negatif terhadap communication apprehension. Hal tersebut dapat diartikan bahwa semakin tinggi efikasi diri maka semakin rendah communication apprehension dan sebaliknya

Kata kunci: communication apprehension, efikasi diri, mahasiswa

\section{PENDAHULUAN}

Permasalahan yang sering terjadi pada era sekarang adalah gangguan berkomunikasi. Dalam perkembangan proses pembelajaran mahasiswa kemampuan komunikasi yang baik semestinya sudah dikuasai oleh setiap mahasiswa dalam menunjang pembelajaran. Selain itu, kemampuan beradaptasi yang baik akan tumbuh dari proses kemampuan komunikasi seseorang yang ini dimaksud adalah, bagaimana mahasiswa mampu menyesuaikan dirinya dengan staf pengajar (dosen), sistem pembelajaran, dan yang terpenting bagaimana mahasiswa mampu menyesuaikan cara berkomunikasi dengan staf pengajar dan teman-teman di kampus.

Rakhmat (2012) menambahkan bahwa dengan berkomunikasi manusia dapat belajar banyak hal, membangun hubungan dengan orang lain dan melestarikan peradaban. Pada kenyataannya ada mahasiswa baru yang mengalami kesulitan dalam berkomunikasi dengan orang lain, baik dalam proses belajar di kelas maupun dalam suasana informal di luar kelas. Mahasiswa baru merasa takut, khawatir, ragu-ragu, dan terlihat gemetar serta mengeluarkan banyak keringat ketika berkomunikasi dengan orang lain.

Dalam penelitian lain mengenai kemampuan komunikasi menyebutkan, salah satu meningkatkan kemampuan

\footnotetext{
*Korespondensi Penulis: nurfitriyana@umri.ac.id
}

efikasi diri adalah dengan cara memberikan latihan komunikasi yang baik. Hal ini disampaikan Suseno (2009) dalam penelitiannya mengenai pelatihan komunikasi interpersonal dalam meningkatkan efikasi diri.

Dalam komunikasi pada umumnya, didapatkan adanya gangguan-gangguan dalam berkomunikasi yang dikenal dengan nama communication apprehension, yaitu sebuah reaksi negatif dalam bentuk kecemasan yang dialami seseorang dalam pengalaman komunikasinya (Rakhmat, 2012). Sebuah penelitian di Amerika menyatakan bahwa 10-20\% mahasiswa Amerika menderita communication apprehension (McCroskey, 1978). Orang yang mengalami hal tersebut berusaha sekecil mungkin berkomunikasi yang disebabkan adanya kecemasan, diantaranya adalah rasa takut menerima tanggapan atau penilaian negatif dari komunikan atau orang yang menerima pesan. Orang yang mengalami communication apprehension akan merasa sulit dan merasa cemas ketika harus berkomunikasi dengan orang lain, sehingga tidak mampu mencerminkan rasa kehangatan, keterbukaan, dan dukungan.

Penanganan kecemasan antar satu individu dengan individu lainnya dapat berbeda tergantung pada penilaian pribadi individu terhadap kemampuan yang dimilikinya yang disebut efikasi diri. Bandura (1997) mendefinisikan efikasi diri sebagai keyakinan individu mengenai kemampuan dirinya dalam melakukan tugas atau tindakan yang 
Versi Online: http://journal.ubm.ac.id/index.php/psibernetika DOI: 10.30813/psibernetika. v13i2.2322 Hasil Penelitian

diperlukan untuk mencapai hasil yang baik. Berdasarkan berbagai ulasan di atas peneliti dapat menyimpulkan bahwa pelatihan efikasi diri komunikasi dapat diberikan sebagai upaya untuk mengurangi gejala communication apprehension pada mahasiswa baru.

Hipotesis yang diajukan dalam penelitian ini adalah efikasi diri komunikasi dapat menurunkan tingkat communication apprehension pada mahasiswa baru. Semakin tinggi efikasi diri komunikasi pada mahasiswa maka tingkat communication apprehension semakin rendah. Sebaliknya jika semakin rendah efikasi diri komunikasi mahasiswa maka tingkat communication apprehension semakin tinggi.

\section{Communication Apprehension}

Communication apprehension
adalah sebuah reaksi cemas atau ketakutan untuk melakukan komunikasi (Rakhmat, 2012). McCroskey (1984) mendefinisikan communication apprehension sebagai tingkat kekhawatiran atau kecemasan individu yang berhubungan dengan komunikasi yang sedang atau akan dilakukan dengan orang lain. Sedangkan menurut Littlejhon dan Foss (2011) communication apprehension merupakan kecenderungan untuk cemas saat berkomunikasi dalam berbagai keadaan.

Menurut Burgoon dan Ruffner (1978) communication apprehension adalah suatu reaksi negatif dari individu berupa kecemasan yang dialami individu ketika berkomunikasi, baik komunikasi antar pribadi, komunikasi di depan umum, ataupun komunikasi masa. Kecemasan dalam melakukan komunikasi diungkapkan oleh West dan Turner (2008) sebagai kecemasan komunikasi yaitu ketakutan berupa
Jurnal Psibernetika

Vol.13 (No.2) : 83-91. Th. 2020

p-ISSN: 1979-3707

e-ISSN: 2581-0871

perasan negatif yang dirasakan individu dalam melakukan komunikasi, biasanya berupa perasaan tegang, gugup atau pun panik ketika melakukan komunikasi. Hal ini sama seperti yang di kemukakan oleh Sellnow dan Ahlfeldt (2005) bahwa kecemasan dalam komunikasi dapat diartikan sebagai ketakutan atau kekhawatiran individu yang berkaitan dengan komunikasi nyata dengan orang lain.

Berdasarkan penjelasan di atas dapat disimpulkan bahwa communication apprehension yaitu ketakutan, kekhawatiran, berupa perasaan negatif yang dirasakan individu dalam melakukan komunikasi pada situasi tertentu, baik dalam situasi komunikasi yang nyata ataupun komunikasi yang akan dilakukan individu dengan orang lain maupun dengan orang banyak.

\section{Aspek-Aspek}

Communication

Apprehension

Menurut Patterson dan Ritts (Littejohn dan Foss, 2011) sejumlah parameter yang mengidikasikan seseorang mengalami communication apprehension meliputi :

a. Aspek fisiologis, seperti ketegangan motorik (sakit perut, sakit kepala, gemetar, suara gemetar) dan overaktifitas otonomik (detak jantung semakin cepat, wajah memerah, tubuh gemetar, tangan dan kaki berkeringat).

b. Aspek perilaku, seperti melakukan penghindaran (diam atau tidak hadir) dan proteksi diri (tidak mengalihkan pandangan dari audience atau tuutp muka dengan kertas) terhadap situasi yang menuntutnya untuk berkomuniksi.

c. Apek kognitif, seperti berfokus diri dan pikiran negatif. Individu yang mengalami 
Versi Online: http://journal.ubm.ac.id/index.php/psibernetika DOI: 10.30813/psibernetika. v13i2.2322

Hasil Penelitian

apprehension ditinjau dari dimensi kognitif.

\section{Efikasi Diri}

Bandura (dalam Pajares, 2002) mendefinisikan efikasi diri sebagai perasaan yang dimiliki individu bahwa dirinya cakap dan mampu melakukan tindakan-tindakan yang tepat. Efikasi diri mengandung makna kepercayaan diri yang dimiliki seseorang untuk menggorganisasikan dan memiliki tindakan yang diperlukan dalam menghadapi situasi khusus yang mungkin terdapat kekaburan, tidak dapat diprediksi, dan penuh tekanan. Efikasi diri mengacu pada keyakinan akan kemampuan-kemampuan individu untuk memenuhi tuntutan situasi. Semakin kuat efikasi diri seseorang, maka semakin besar kemungkinan seseorang akan memilih tugas atau situasi yang menantang agar mencapai sebuah keberhasilan.

Bandura (dalam Alwisol, 2009) mengemukakan bahwa efikasi diri adalah penilaian diri, apakah dapat melakukan tindakan yang baik atau buruk, tepat atau salah, bisa atau tidak bisa mengerjakan sesuai yang di persyaratkan. Efikasi diri menggambarkan penilaian kemampuan diri. Sedangkan Baron \& Byrne mendefinisikan (2003) efikasi diri adalah keyakinan seseorang akan kemampuanya atau kompetensinya atas kinerja tugas yang di berikan, mencapai tujuan, atau mengatasi sebuah hambatan. Evaluasi ini dapat bervariasi, tergantung pada situasi.

Hal serupa juga didefinisikan Yusuf (2007) bahwa self efficacy merupakan keyakinan diri (sikap percaya diri) terhadap kemampuan sendiri untuk menampilkan tingkah laku yang akan mengarahkanya kepada hasil yang di harapkan. Menurut Bandura
Jurnal Psibernetika

Vol.13 (No.2) : 83-91. Th. 2020

p-ISSN: 1979-3707

e-ISSN: 2581-0871

(1997) efikasi diri dapat diperoleh, diubah, dtingkatkan atau diturunkan melalui salah satu atau kombinasi empat sumber efikasi diri, yaitu :

a. Mastery experience

Pengalaman menyelesaikan masalah adalah sumber yang paling penting mempengaruhi efikasi diri seseorang, karena mastery experience memberikan bukti yang paling akurat dari tindakan apa saja yang diambil untuk meraih suatu keberhasilan atau kesuksesan, dan keberhasilan tersebut dibangun dari kepercayaan yang kuat di dalam keyakinan individu. Kegagalan akan menentukan efikasi diri individu terutama bila perasaan keyakinannya belum terbentuk dengan baik. Jika individu hanya mengalami keberhasilan/kesuksesan dengan mudah, individu akan cenderung mengharapkan hasil yang cepat dan mudah menjadi lemah karena kegagalan. Padahal beberapa kegagalan dan rintangan dalam usaha manusia mengajarkan bahwa kesuksesan membutuhkan kerja keras. Setelah individu diyakinkan bahwa individu tersebut memiliki hal-hal yang diperlukan untuk mencapai kesuksesan, individu akan berusaha untuk bangkit dan keluar dari kegagalan, karena efikasi diri yang kuat membutuhkan pengalaman menghadapi rintangan melalui usaha yang tekun.

b. Vicarious experience

Pengalaman orang lain adalah pengalaman pengganti yang disediakan untuk model sosial. Mengamati perilaku dan pengalaman orang lain sebagai proses belajar individu. Melalui model ini efikasi diri individu dapat meningkat, terutama apabila individu merasa memiliki kemampuan yang setara 
atau bahkan merasa lebih baik dari pada orang yang menjadi subjek belajarnya. Individu akan mempunyai kecenderungan merasa mampu melakukan hal yang sama. Meningkatkan efikasi diri individu ini dapat meningkatkan motivasi untuk mencapai tujuan yang diharapkan. Melihat orang lain yang mirip dengan dirinya berhasil/sukses melalui usaha keras dapat meningkatkan kepercayaan pengamat bahwa dirinya juga mempunyai kemampuan untuk berhasil, dan sebaliknya dengan mengamati kegagalan orang lain akan menurunkan keyakinan dan usaha dari individu tersebut.

Dampak modeling dalam efikasi diri sangat dipengaruhi oleh kemiripan antara individu dengan model. Semakin mirip individu dengan suatu model, maka pengaruh kegagalan maupun keberhasilannya akan semakin besar. Jika modelnya jauh berbeda dari individu, maka tidak akan banyak mempengaruhi efikasi diri. Peningkatan efikasi diri akan menjadi efektif apabila subjek yang menjadi model tersebut mempunyai banyak kesamaan karakteristik antara individu dengan model, kesamaan tingkat kesulitan tugas, kesamaan situasi dan kondisi, serta keanekaragaman yang dicapai oleh model.

c. Verbal Persuasion

Verbal persuasion adalah cara ketiga untuk meningkatkan kepercayaan seseorang mengenai hal-hal yang dimilikinya untuk berusaha lebih gigih untuk mencapai tujuan dan keberhasilan/kesuksesan. Verbal persuasion mempunyai pengaruh yang kuat pada peningkatan efikasi diri individu dan menunjukkan perilaku yang digunakan secara efektif. Seseorang mendapat bujukan atau sugesti untuk percaya bahwa dirinya dapat mengatasi masalahmasalah yang akan dihadapinya. Verbal persuasion berhubungan dengan kondisi yang tepat bagaimana dan kapan persuasi itu diberikan agar dapat meningkatkan efikasi diri seseorang. Kondisi individu adalah rasa percaya kepada pemberi persuasi dan sifatnya realistik dari apa yang dipersuasikan. Seseorang yang dikenai Verbal persuasion bahwa dirinya memiliki kemampuan untuk menyelesaikan tugas yang telah diberikan, maka orang tersebut akan menggerakkan usaha yang lebih besar dan akan meneruskan penyelesaian tugas tersebut.

d. Physiological State and Emosional Arousal

Situasi yang menekan kondisi emosional dapat mempengaruhi efikasi diri. Gejolak emosi, goncangan, kegelisahan yang mendalam dan keadaan fisiologis yang lemah yang dialami individu akan dirasakan sebagai isyarat akan terjadi peristiwa yang tidak diinginkan, maka situasi yang menekan dan mengancam akan cenderung dihindari. Ketika melakukan penilaian terhadap kemampuan pribadi, seseorang tidak jarang berpegang pada informasi somatik yang ditunjukkan melalui fisiologis dan keadaan emosional. Individu mengartikan reaksi cemas, takut, stress dan ketegangan sebagai sifat yang menunjukkan bahwa performansi dirinya menurun. Penilaian seseorang terhadap efikasi diri dipengaruhi oleh suasana hati. Suasana hati yang positif akan meningkatkan efikasi diri sedangkan suasana hati yang buruk akan melemahkan efikasi diri. Mengurangi 
Versi Online: http://journal.ubm.ac.id/index.php/psibernetika DOI: 10.30813/psibernetika. v13i2.2322

Hasil Penelitian

reaksi cemas, takut dan stress individu akan mengubah kecenderungan emosi negatif dengan salah interpretasi terhadap keadaan fisik dirinya sehingga akhirnya akan mempengaruhi efikasi diri yang positif terhadap diri seseorang.

Berdasarkan uraian di atas, peneliti menyimpulkan bahwa sumbersumber yang mempengaruhi efikasi diri ialah mastery experience, vicarious experience, persuasi verbal, keadaan fisiologis dan emosional. Sumbersumber tersebut akan menjadi dasar teori dalam membuat modul pelatihan efikasi diri.

\section{METODE PENELITIAN}

Penelitian ini dijalankan secara penelitian survey dengan menggunakan skala penelitian. Populasi dalam penelitian ini adalah mahasiswa tahun pertama. Teknik pengambilan sampel digunakan dalam penelitian ini yaitu quota random sampling. Variabel dalam penelitian ini terdiri dari variabel tergantung (communication apprehension) dan variabel bebas (efikasi diri). Teknik pengolahan data menggunakan teknik analisis regresi linier sederhana. Penelitian menggunakan Skala aspek communication apprehension antara lain aspek fisionlogis, perilaku dan kognitif sedangkan skala efikasi diri meliputi aspek mastery experience, vicarious experience, persuasi verbal, keadaan fisiologis dan emosional. Skala penelitian akan dianalisis menggunakan IBM SPSS Statistic 22.

\section{HASIL DAN PEMBAHASAN}

\section{Hasil}

Uji hipotesis dilakukan dalam mengetahui ada tidaknya pengaruh efikasi
Jurnal Psibernetika

Vol.13 (No.2) : 83-91. Th. 2020

p-ISSN: 1979-3707

e-ISSN: 2581-0871

diri terhadap communication apprehension pada mahasiswa baru tahun pertama Universitas Muhammadiyah Riau. Menggunakan analisis regresi sederhana dengan bantuan program SPSS 20 for Windows.

Berdasarkan hasil analisa data yang didapatkan bahwa efikasi diri memiliki pengaruh terhadap communication apprehension pada mahasiswa baru tahun pertama Universitas Muhammadiyah Riau. Pada tabel 1 menunjukan $\mathrm{r}$ yaitu 0,503 dengan signifikansi 0,000 . Hal ini menunjukan bahwa ada pengaruh efikasi diri terhadap communication apprehension pada mahasiswa baru tahun pertama Universitas Muhammadiyah Riau. Dari hasil uji regresi sederhana bahwa variable efikasi diri berpengaruh terhadap communication apprehension sebesar $17,3 \%$ sedangkan sisanya $82,7 \%$ dipengaruhi oleh faktor lain yang tidak dijelaskan dalam penelitian ini. Skor koefisien pengaruh efikasi diri memiliki persentasi menunjukan skor yang berarah negatif terhadap communication apprehension. Hal tersebut dapat diartikan bahwa semakin tinggi efikasi diri maka semakin rendah communication apprehension dan sebaliknya.

Tabel 1. Uji Regresi

\begin{tabular}{ccc}
\hline $\begin{array}{c}\text { Koefisien } \\
(r)\end{array}$ & $\begin{array}{c}\text { Koefisien } \\
\text { Determinasi }\left(r^{2}\right)\end{array}$ & Sig. $(p)$ \\
\hline 0,503 & 0,173 & 0,000 \\
\hline
\end{tabular}

\section{Pembahasan}

Penelitian ini menunjukan bahwa uji hipotesis diterima. Hal tersebut memiliki arti bawha terdapat pengaruh efikasi diri terhadap communication apprehension yang memiliki arah negative. Terdapat beberapa mahasiswa yang memiliki selfefficacy yang cukup tinggi memandang kesulitan tidak sebagai ancaman tetapi 
Versi Online: http://journal.ubm.ac.id/index.php/psibernetika DOI: 10.30813/psibernetika. v13i2.2322

Hasil Penelitian

sebagai tantangan yang harus ia hadapi. Adanya sebuah tujuan yang jelas dan komitmen yang kuat menjadikan individu terfokus pada usaha yang konsisten untuk mencapainya. Jika individu mempunyai pengalaman kegagalan, maka kegagalan tersebut akan dipandang sebagai pembelajaran dan akan menjadi acuan untuk memotivasi menjadi diri yang lebih baik. Sebaliknya jika individu mengalami sebuah pengalaman dalam keberhasilan, maka individu akan memperkuat keyakinan dirinya dalam menghadapi sebuah situasi. Individu tersebut akan memili pengelolaan kecemasan komunkasi dengan baik.

Sebaliknya diperoleh hasil data dari mahasiswa baru cukup rendah (selfefficacy) yang mereka miliki, individu akan cenderung menghindar dalam menghadapi situasi yang mengancam dan mengalami kecemasan dalam berkomunikasi (communication apprehension). Keraguraguan atas kemampuan dirinya membangun komitmen yang rendah terhadap tujuan pribadi. Situasi atau tugas yang sulit merupakan sebuah hal yang mengancam, sehingga pikiran mereka lebih tertuju pada kelemahan dan kekurangan yang tidak dapat dilakukan untuk mencapai hal yag positif. Kegagalan akan disikapi dengan perasaan putus asa sehingga tidak percaya diri untuk melakukannya kembali. Hal ini akan memicu sebuah kecemasan dan perasaan tertekan yang akibatnya akan mempengaruhi kekondisi fisiknya.

Bandura (dalam Nevid, Spencer, Greene, 2005:183) menyampaikan jika manusia tidak percaya dengan keahliannya dalam menjawab setiap tantangan yang hadir makan mereka akan timbul perasaan yang cemas apabila manusia itu dihadapi oleh tantangan tersebut, dan juga sebaliknya jika individu yakin dengan yang ia miliki dalam menghadapi tantangan maka individu tersebut tidak akan mengalami kecemasan.
Jurnal Psibernetika

Vol.13 (No.2) : 83-91. Th. 2020

p-ISSN: 1979-3707

e-ISSN: 2581-0871

Hal inilah yang sering terjadi pada mahasiswa baru.

Perbedaan self-efficacy inilah yang akan menentukan keberhasilan mahasiswa baru dalam menghadapi sebuah komunikasi interpersonal. hal tersebut sesuai dengan yang dikemukakan oleh Bandura (1997) bahwa self-efficacy diri akan mempengaruhi beberapa aspek dari kognisi dan perilaku seseorang, sehingga perilaku individu akan berbeda dengan individu lainnya. individu yang memiliki self-efficacy yang tinggi maka tingkat kecemasan komunikasi interpersonalnya semakin rendah karena saat individu merasa cemas yang muncul pada saat ia harus berkomunikasi interpersonal dapat diatasi dan dikelola bahkan dapat dijadikan pendorong usahanya untuk mendapatkan isyarat tentang situasi komunikasi tersebut, sehingga individu dapat berkomunikasi interpersonal dengan baik dan efektif. Selain itu karena merasa yakin dengan kemampuaannya individu yang memiliki self-efficacy tinggi akan berusaha lebih keras dan bertahan lebih lama dalam menghadapi kesulitan-kesulitan atau hambatan-hambatan yang mungkin muncul.

Individu dengan self-efficacy yang tinggi akan mampu mengendalikan situasi yang berbahaya sehingga tidak merasa cemas dan tidak merasa terusik oleh situasi mengancam tersebut. Begitu pula sebaliknya, jika seseorang yang memiliki self-efficacy yang rendah, maka seseorang kurang mampu mengatasi situasi yang mengancam dan akan mengalami sebuah kecemasan.

Kecemasan merupakan hal yang pernah dialami oleh setiap individu. Begitu juga dengan mahasiswa yang baru saja menduduki sebuah tingkat perguruan tinggi, mahasiswa baru seringkali cemas untuk 
Versi Online: http://journal.ubm.ac.id/index.php/psibernetika DOI: 10.30813/psibernetika. v13i2.2322 Hasil Penelitian

memulai pembicaraan atau berkomunikasi dengan orang baru mereka kenal. Hal ini tentu saja akan berpengaruh terhadap proses perkuliahan mahasiswa tersebut, seperti kurangnya teman di lingkungan kampus, sulit berkomunikasi, bahkan mungkin saja akan mempengaruhi hasil akademik mereka.

Kenyataanya dalam sebuah komunikasi interpersonal terdapat hambatan-hambatan dalam berkomunikasi, yang disebut dengan istilah communication aprehension, yaitudi mana seseorang mengalami suatu keadaan yang tidak nyaman, dalam menghadapi situasi berkomunikasi dengan orang lain atau kelompok yang ditandai dengan adanya ciri-ciri kecemasan. Cemas interpersonal ini disebabkan karena kurangnya kepercayaan diri ketika menghadapi sebuah situasi komunikasi interpersonal. Untuk mengatasi hal tersebut diperlukan adanya self-efficacy yang tinggi untuk mengurangi rasa kecemasan yang dihadapi oleh idividu. Karena self-efficacy mampu mempengaruhi individu dan menentukan keberhasilan dalam menghadapi sebuah komunikasi interpersonal tersebut. Semakin tinggi selfefficacy mahasiswa baru, maka akan semakin rendah tingkat kecemasan komunikasi interpersonal dan akan menganggap dirinya mampu mengatasi situasi yang mengancam, begitu pula sebaliknya, mahasiswa baru yang memiliki self-efficacy yang rendah akan memiliki kecemasan komunikasi interpersonal yang tinggi, karena merasa tidak mampu mengatasi situasi yang mengancam.

\section{SIMPULAN}

Berdasrkan pnelitian ini, dapat diperoleh kesimpulan bahwa terdapat pengaruh efikasi diri terhadap communication apprehension pada
Jurnal Psibernetika

Vol.13 (No.2) : 83-91. Th. 2020

p-ISSN: 1979-3707

e-ISSN: 2581-0871

mahasiswa baru tahun pertama Universitas Muhammadiyah Riau. Skor koefisien pengaruh efikasi diri memiliki persentasi menunjukan skor yang berarah negatif terhadap communication apprehension. Hal tersebut dapat diartikan bahwa semakin tinggi efikasi diri maka semakin rendah communication apprehension dan sebaliknya.

\section{DAFTAR PUSTAKA}

Alwisol. (2009). Psikologi kepribadian. Malang: UMM press.

Ahmadi, Abu \& Sholeh, Munawar. (1991). Psikologi perkembangan. Jakarta: Rineka Cipta

Atkitson R.L., Atkinson R.C., Smith E.E., Bem D.J. 2002. Stres dan mengatasinya. Dalam: Pengantar psikologi. Terjemahan Widjaja Kusuma. Batam: Interaksara.

Azwar, S. (2007). Penyusunan skala psikologi. Yogyakarta: Pustaka Pelajar.

Bandura, A. (1994). Self-efficacy. New York: Academic press.

Bandura, A. (1997). Self efficacy: the exercise of control. New york: W.H Freeman and Company.

Baron, R. A., \& Byrne, D. (2003). Psikologi sosial. (W. C. Kristiaji, R. Medya, Penyunt., \& R. Djuwita, Penerj.) Jakarta: Erlangga.

Greenberg, D., \& Padesky, C. (2004). Manajemen pikiran: Metode ampuh untuk mengatasi depresi, kemarahan, kecemasan dan perasaan merusak lainnya. Bandung: Kaifa.

Gunarsa, Singgih \& Gunarsa, Yulia. (2001). Psikologi praktis anak, remaja dan keluarga. Jakarta: Gunung Mulia.

Hartaji, Damar A. (2012). Motivasi berprestasi pada mahasiswa yang berkuliah dengan jurusan pilihan orangtua. Fakultas Psikologi Universitas Gunadarma. (tidak diterbitkan)

Hasbi, F. F. (2016). Evektivitas pelatihan efikasi diri akademik untuk 
Versi Online: http://journal.ubm.ac.id/index.php/psibernetika DOI: 10.30813/psibernetika. v13i2.2322

Hasil Penelitian

menurunkan kecemasan akademik pada siswa akselerasi. Tesis. Universitas Islam Indonesia.

Irwansya. (2008). Hubungan antara communication apprehension, cellphone apprehension, usability dan motif komunikasi interpersonal pada pengguna telepon genggam. Tesis. Jakarta, Universitas Indonesia: Tidak diterbitkan.

Kartono, K., \& Gulo, D. (2003). Kamus psikologi. Bandung: Pionir Jaya Press

Lazarus, R.S. (1976). Paterns of adjusment. Tokyo: McGraw-Hill, Kogakusha, Ltd.

Lailatushifah, S. N. F. (2004). Peran efikasi diri, optimisme, dukungan dosen pembimbing, terhadap stres mahasiswa yang sedang menyusun skripsi. Tesis. Fakultas Psikologi UGM. Tidak diterbitkan

Littlejhon, L., \& Foss, K. (2011). Teori komunikasi (Ed.9). Jakarta: Salemba Humanika.

McCroskey, J.C. (1984). Avoiding communication: shyness, reticence, and communication apprehension. California: Sage.

Mulyana, D. (2005). Ilmu komunikasi. Bandung: PT Remaja Rosdakarya.

Myers, A., \& Hansen, C.H. (2002). Experimental psychology. Wadsworth Group.

Narbuko, C.,, \& Achmadi, a. (2003). Metodologi penelitian. Jakarta: Bumi Aksara.

Narbuko, C., \& Achmadi, A. (2003). Metodologi penelitian. Jakarta: Bumi Askara.

Nurlaila, S. (2011). Pelatihan efikasi diri untuk menurunkan kecemasan pada siswa-siswi yang akan menghadapi ujian akhir nasional. Jurnal. Guidena l(1), 1-22.

Ottens, A.J. (1991). Coping with academic anxiety. New York: The Rosen Publishing Group

Pajares. (t.thn.). Overview of social cognitive theory and of self-efficacy. Dipetik Desember 9, 2011, dari
Jurnal Psibernetika

Vol.13 (No.2) : 83-91. Th. 2020

p-ISSN: 1979-3707

e-ISSN: 2581-0871

http://www.emory.edu/Education/mf p/eff.html.

Powell. R \& Powell. D. (2010). Classroom communication and diversity. NewYork : Routlege

Rachmi, E., \& Khotimah, S. (2010). Reducing public communication apprehension by boosting self confidence on communication apprehension competence. Health Science Indonesia, 1(1), 1-6.

Rakhmat, J. (2012). Psikologi komunikasi. Bandung: PT Remaja Rosdakarya.

Sellnow, D., \& Ahlfeldt, S. (2005). Fostering critical thinking and teamwork skills via problem-based learning (PBL) approach to public speaking fundamentals. Communication Teacher, 19(1), 3338.

Sugiyono. (2003). Statistika untuk penelitian. Bandung: Alfabeta.

Suseno, M.N.M. (2009). Pengaruh pelatihan komunikasi interpersonal terhadap efikasi diri sebagai pelatih pada mahasiswa. Jurnal Intervensi Psikologi, 1(1), 93-106.

Weiten, W., Llyod, M., Dunn, D., \& Hammer, E. (2009). Psychology applied to modern life. USA: Wadswort Cingengange Learning.

West, R., \& Turner, L. H. (2008). Pengantar teori komunikasi. Jakarta: Selemba Humanika.

Widiantoro, D., Sukarti, S., \& Budiharto, S. (2017). Pelatihan komunikasi interpersonal untuk meningkatkan kohesivitas kelompok pada karyawan Hotel X Yogyakarta. JIP: Jurnal Intervensi Psikologi, 9(2), 155-168.

Yusuf, S. (2007). Teori kepribadian. Bandung: Remaja rosdakarya. 